\title{
Globe
}

Revue internationale d'études québécoises

\section{Lise Gauvin, Aventuriers et sédentaires : parcours du roman québécois, Paris, Éditions Honoré Champion, 2012 ; Montréal, Editions Typo, 2014}

\section{Doris G. Eibl}

Volume 17, numéro 1, 2014

URI : https://id.erudit.org/iderudit/1028644ar

DOI : https://doi.org/10.7202/1028644ar

Aller au sommaire du numéro

Éditeur(s)

Globe, Revue internationale d'études québécoises

ISSN

1481-5869 (imprimé)

1923-8231 (numérique)

Découvrir la revue

Citer ce compte rendu

Eibl, D. G. (2014). Compte rendu de [Lise Gauvin, Aventuriers et sédentaires : parcours du roman québécois, Paris, Éditions Honoré Champion, 2012 :

Montréal, Éditions Typo, 2014]. Globe, 17(1), 238-241.

https://doi.org/10.7202/1028644ar d'utilisation que vous pouvez consulter en ligne.

https://apropos.erudit.org/fr/usagers/politique-dutilisation/ 
La communication politique peut étudier de diverses façons ce "glissement progressif» de la présence politique dans des émissions plus légères, qui ont souvent peu à voir avec l'information et les affaires publiques. Le divertissement au sens pascalien du terme apparaît de plus en plus comme condamnable, mais les politiciens, sous les pressions de leurs conseillers, peuvent difficilement éviter la tentation de jouer le jeu et de se présenter devant les larges auditoires canalisés par ce type d'émission. En ce sens, l'attitude de Frédérick Bastien envers ce phénomène est juste : il évite de dénigrer ou de disqualifier l'infodivertissement sans pour autant l'endosser ou le légitimer, car là n'est pas son propos. Dans la limite de ses moyens, il invite ses collègues à scruter les médias de masse pour les analyser et tenter de comprendre comment les vérités apparemment immuables de l'infodivertissement réussissent à obtenir tant de visibilité. Il évite par contre d'aborder la question fondamentale qui reste en suspens : est-ce le mandat de RadioCanada de proposer dans sa grille - qui plus est aux heures de grande écoute - des émissions accrocheuses comme Infoman et Tout le monde en parle, qui constituent désormais, que cela nous plaise ou non et en dépit de leurs graves lacunes, la principale source d'information de beaucoup de gens à propos des affaires publiques et bien souvent leur seul contact avec les politiciens d'ici. Comme l'indique Frédérick Bastien dans sa conclusion optimiste, cette étude du petit écran est un des principaux défis des universitaires qui s'intéressent au rôle de la télévision dans une société pluraliste, à une époque où l'on semble avoir oublié l'idéal télévisuel d'autrefois (p. 176).

Yves Laberge

Université Laval

\section{Lise Gauvin}

Aventuriers et sédentaires : parcours du roman québécois, Paris, Éditions Honoré Champion, 2012 ; Montréal, Éditions Typo, 2014.

Professeure émérite de l'Université de Montréal et écrivaine, Lise Gauvin est de ceux dont l'œuvre critique élaborée au cours des décennies passées a balisé de façon décisive la réception universitaire de la littérature québécoise, notamment celle extra-muros. Ayant eu recours, au début des années 1990, au qualificatif d'«âge de la prose » pour désigner un certain dé- 
placement paradigmatique observé dans la littérature québécoise des années 1980, elle a contribué alors, par l'évocation de quelques " points névralgiques ", à établir une grille de lecture qui a orienté le regard critique sur la littérature contemporaine du Québec vers des thèmes tels que la ville, le voyage, le féminin ou la migration, pour ne nommer que les plus éminents. Plus que d'autres, cependant, Lise Gauvin a placé ses recherches sous le signe de la langue, en s'intéressant plus spécialement à la «surconscience linguistique de l'écrivain " dans un contexte francophone en général et dans celui du Québec en particulier. Ainsi, dans Langagement: l'écrivain et la langue au Québec (2000), le parcours de lecture critique proposé par l'auteure s'étend des premières ébullitions en matière d'engagement linguistico-littéraire chez Octave Crémazie et l'abbé Henri-Raymond Casgrain jusqu'aux enjeux transculturels et plurilinguistiques dans les littératures migrantes de la fin du $\mathrm{XX}^{\mathrm{e}}$ siècle, en passant par l'écriture réaliste, le mouvement partipriste, les théories-fictions au féminin, le théâtre de Michel Tremblay et l'œuvre ducharmienne, entre autres.

Paru aux Éditions Honoré Champion dans la collection «Unichamp-Essentiel » dirigée par les comparatistes Jean Bessière et Denis Mellier, Aventuriers et sédentaires: parcours du roman québécois s'inscrit dans une certaine continuité, nous semble-t-il, avec l'approche forgée dans Langagement. Tout en définissant de nouvelles priorités - il s'agit, comme le suggère le sous-titre, de présenter le roman québécois dans une perspective historique -, ce volume destiné « aux étudiants, aux enseignants et à un large public " (quatrième de couverture) fait amplement écho, tant sur le plan méthodologique que sur le plan thématique, aux travaux antérieurs de Lise Gauvin, nous offrant de la sorte le condensé de son immense savoir littéraire. Réaffirmant comme axe d'analyse la relation toute particulière que l'écrivain québécois entretient avec la langue, l'auteure développe son parcours du roman québécois autour de sept chapitres consacrés respectivement aux questions de langue, à l'écrivain et l'écrivant comme personnages de roman, à la dichotomie identitaire représentée par les figures mythiques de l'aventurier et du sédentaire, à la géographie culturelle, littéraire et linguistique de Montréal, au thème du voyage, aux écritures au féminin et, en dernier point, mais non le moindre en nombre de pages, aux écritures dites migrantes. Si, dès l'introduction, elle nous rappelle que « les créateurs [québécois] d'aujourd'hui héritent d'une littérature et n'hésitent pas à inscrire leurs œuvres dans une tradition littéraire dont ils s'inspirent en toute liberté » (p. 15), c'est peut-être pour mieux nous initier à sa démarche plutôt exigeante pour un projet d'étude d'ensemble comme celui d'Aventuriers et sédentaires. Au lieu 
d'identifier, par souci de simplification, un thème à une époque, Lise Gauvin conduit ses lecteurs de chapitre en chapitre, déclinant les sujets respectifs dans une perspective de longue durée et convoquant une multiplicité de voix qui nous montre à la fois la diversité des points de vue à une même époque et le dialogisme à l'œuvre entre les générations.

Le choix de Lise Gauvin d'amorcer son parcours du roman québécois par un chapitre dédié aux relations complexes de l'écrivain québécois à la langue nous paraît pertinent à plus d'un titre. Au-delà du fait que, ce faisant, elle renouvelle une méthode d'approche déjà éprouvée, l'idée de confronter le lecteur, dès le départ, à une problématique en même temps spécifiquement québécoise et universelle, est des plus heureuses. S’il est vrai que « [d] epuis ses origines [...], la littérature québécoise est traversée et hantée par une problématique de la langue qui dépasse les seuls enjeux lexicaux et met en cause son propre statut ainsi que la nature de son fonctionnement" (p. 17), toute littérature, suivant son contexte et ses préoccupations, est hantée par la langue et plus encore par l'" estrangement» ou l'éloignement qui se met en place dès que la langue devient littérature et qu'elle ne va plus de soi.

Ainsi, rien de plus logique que d'enchaîner en suivant ceux qui incarnent le plus authentiquement cette langue qui ne va pas de soi. Dans un deuxième chapitre ("Le romancier et ses doubles : écrire, disent-ils», p. 4579), Lise Gauvin rassemble de nombreux personnages-écrivains, des "écrivants " aussi, qui font du roman québécois un véritable forum de réflexion ou d'autoréflexion linguistique et littéraire. L'écriture y est de tous les espoirs et de tous les désirs, de tous les possibles et de tous les impossibles, conviant à la vie ou menant à la chute. Les personnages-écrivains, tantôt idéalistes (Denis Boucher dans Au pied de la pente douce, 1945) ou existentialistes (Hervé Jodoin dans Le Libraire, 1960), tantôt révolutionnaires (le narrateur dans Prochain épisode, 1965) ou ethnographes (François Galarneau dans Salut Galarneau!, 1967), créateurs d'inspiration rimbaldienne (dans les romans de Réjean Ducharme), aux identités incertaines (Anne dans Double suspect, 1980 ; Block dans L'Emprise, 1979) ou grands dépressifs (Alexandre dans Le milieu du jour, 1995), interrogent les rapports entre littérature et société, entre le fictif et le réel, mesurant inlassablement l'étendue de l'estrangement séculaire entre les mots et les choses. Lorsqu'ils sont voyageurs (chapitre 5, «Il était une fois dans l'ouest: les road novels québécois », p. 131-157), leur " usage du monde " s'avère souvent une impasse. Citadins (chapitre 4, "Comment peut-on être Montréalais : une ville et ses fictions ", 109-129), ils arpentent leur ville de long en large, se font archéologues de culture (Maryse, 1983 ; Myriam première, 1987) ou miroir d'une ville fragmentée ( $L a$ 
Québécoite, 1983). Si l'on veut croire Lise Gauvin, «[c]ette omniprésence de l'écrivain fictif signale [...] un certain inconfort et une certaine intranquillité quant à la fonction même de l'écriture, comme s'il fallait répondre à une question d'autant plus sournoise qu'elle est implicite: "À quoi sert la littérature ?” " (p. 79), question de portée universelle, elle aussi.

Si le parcours du roman québécois proposé par Lise Gauvin est, certes, axé sur les questions de langue et d'écriture, vouloir subsumer l'ensemble du volume sous cette seule thématique serait cependant réducteur et ne rendrait aucunement justice aux nombreuses pistes de lecture que l'auteure nous indique à côté et au-delà de la problématique linguistique. Sa fresque est décidément polychrome et, quoique la synthèse des écritures au féminin (chapitre 6, "Théories-fictions, autofictions, romans-poèmes et territoires du féminin ", p. 159-177) soit nécessairement menée le long d'une ligne de réflexion sur la langue et l'auctoritas dans et par l'écriture, elle pointe également vers d'autres thèmes clés, dont la filiation et la mémoire (Suzanne Jacob, Catherine Mavrikakis). Il en va de même, d'ailleurs, pour son synopsis des écritures migrantes (chapitre 7, "Ces "étrangers du dedans" : l'écriture dite migrante", 181-219), où elle appréhende, à côté du plurilinguisme et de la pseudo-traduction, des concepts d'importance tels que la mémoire divisée, le métissage, l'auto-engendrement ou encore l'étrangeté comme posture existentielle.

Retenons que le Québec des "aventuriers et sédentaires" (chapitre 3, «Aventuriers et sédentaires: l'héritage du conte», p. 81-107) a une littérature et que cette littérature a une histoire. On pourrait penser que, de nos jours, cela va sans dire, mais Lise Gauvin, en revenant, dans l'introduction à ce volume publié en France, sur la question d'une double problématique, celle du statut de la littérature québécoise par rapport au centre français et celle de son "étrangéité dans le continent américain " (p. 15), nous en détrompe : la littérature québécoise a beau posséder «ses propres systèmes d'édition, de légitimation et de consécration » (p. 9), elle n'en reste pas moins une "littérature de l'intranquillité" (p. 16), nous dit-elle. N'est-ce pas là son plus grand atout? Son intranquillité nous paraît comme un signe de vie, comme aurait probablement dit Thomas Bernhard tout en s'indignant auprès de la maison d'édition de lire sur la page de couverture «roman québecois » à la place de « roman québécois » et refusant, par ailleurs, d'écrire des «roads novels" à la place de «road novels », malgré son faible pour les belles voitures, notamment pour les Triumph Herald.

Doris G. Eibl

Institut für Romanistik

Universität Innsbruck 